\title{
Effect of Annealing on the Properties of Antimony Telluride Thin Films and Their Applications in CdTe Solar Cells
}

\author{
Zhouling Wang, Yu Hu, Wei Li, Guanggen Zeng, Lianghuan Feng, \\ Jingquan Zhang, Lili Wu, and Jingjing Gao \\ College of Materials Science and Engineering, Sichuan University, Chengdu 610064, China \\ Correspondence should be addressed to Wei Li; waylee2000@sohu.com and Guanggen Zeng; 1838980954@qq.com
}

Received 28 October 2013; Accepted 31 December 2013; Published 20 February 2014

Academic Editor: Dionissios Mantzavinos

Copyright (c) 2014 Zhouling Wang et al. This is an open access article distributed under the Creative Commons Attribution License, which permits unrestricted use, distribution, and reproduction in any medium, provided the original work is properly cited.

\begin{abstract}
Antimony telluride alloy thin films were deposited at room temperature by using the vacuum coevaporation method. The films were annealed at different temperatures in $\mathrm{N}_{2}$ ambient, and then the compositional, structural, and electrical properties of antimony telluride thin films were characterized by X-ray fluorescence, X-ray diffraction, differential thermal analysis, and Hall measurements. The results indicate that single phase antimony telluride existed when the annealing temperature was higher than $488 \mathrm{~K}$. All thin films exhibited p-type conductivity with high carrier concentrations. Cell performance was greatly improved when the antimony telluride thin films were used as the back contact layer for CdTe thin film solar cells. The dark current voltage and capacitance voltage measurements were performed to investigate the formation of the back contacts for the cells with or without $\mathrm{Sb}_{2} \mathrm{Te}_{3}$ buffer layers. CdTe solar cells with the buffer layers can reduce the series resistance and eliminate the reverse junction between $\mathrm{CdTe}$ and metal electrodes.
\end{abstract}

\section{Introduction}

CdS/CdTe thin film solar cells have attracted much technological interest due to their remarkably low cost and high conversion efficiency of $19.6 \%$ [1]. One of the key issues in CdTe solar cells is the high electron affinity; therefore, a high work function metal is required to form a good ohmic contact to p-type CdTe [2]. An approach to overcome this problem is to incorporate a buffer layer between the CdTe and the metal electrodes [2]; that is, materials doped with $\mathrm{Cu}$ or even a $\mathrm{Cu}$ layer have been used to form back contacts, such as $\mathrm{ZnTe}: \mathrm{Cu}$ [3], $\mathrm{Cu} / \mathrm{Au}$ [4], $\mathrm{Cu} /$ graphite [4], and $\mathrm{Cu} / \mathrm{Mo}$ [5]. However, $\mathrm{Cu}$ will diffuse into the main junction and may influence the stability of the cells [6]. In order to form a stable and effective back contact, Romeo et al. [7, 8] fabricated CdS/CdTe solar cells using $\mathrm{Sb}_{2} \mathrm{Te}_{3}$ thin films as a back contact. These solar cells show the high efficiency of $14.6 \%$ and long-term device stability.

Different methods have been used to prepare $\mathrm{Sb}_{2} \mathrm{Te}_{3}$ thin films, such as physical vapor deposition [6], radio frequency magnetron sputtering [7], electrochemical deposition [9], thermal evaporation [10], and metal organic chemical vapor deposition [11]. Arun and Vedeshwar [12] found that the resistance of the polycrystalline $\mathrm{Sb}_{2} \mathrm{Te}_{3}$ films strongly depends on the grain size and intergranular voids. Fang et al. [13] investigated the effects of annealing on thermoelectric properties of $\mathrm{Sb}_{2} \mathrm{Te}_{3}$ thin films. Hu et al. [14] studied the properties of $\mathrm{CdTe} / \mathrm{Sb}_{2} \mathrm{Te}_{3}$ interfaces and the role of $\mathrm{Sb}$ in CdTe solar cells.

In this work, $\mathrm{Sb}_{2} \mathrm{Te}_{3}$ thin films were prepared at room temperature by a vacuum coevaporation method, and the effect of annealing on the properties of thin films and performance of $\mathrm{CdS} / \mathrm{CdTe}$ thin film solar cells were investigated.

\section{Experimental Details}

Antimony telluride thin films were deposited on glass substrates by the vacuum coevaporation method. The vacuum system had a base pressure of $6 \times 10^{-4} \mathrm{~Pa}$ and the Te powder of $5 \mathrm{~N}$ (99.999\%) purity and Sb ingot of $5 \mathrm{~N}$ (99.999\%) purity supplied by Alfa Aesar (USA) were used as the starting materials. The $\mathrm{Sb}$ and $\mathrm{Te}$ deposition rates were measured by two LHC-2 quartz monitors. The as-deposited films were 
annealed at different temperatures in $\mathrm{N}_{2}$ ambient. The film thickness was measured by using a stylus surface profiler and the composition of the thin films was measured by Xray fluorescence $(\mathrm{XRF})$. The structure of the samples was investigated by X-ray diffraction (XRD), using $\mathrm{CuK} \alpha(\lambda=$ $0.154184 \mathrm{~nm}$ ) radiation. Dark conductivity was measured using a two-probe technology. The four-probe Van der Pauw method was used to carry out the Hall measurements to determine the mobility and carrier concentration. The asdeposited films were cleaved from the substrates; then the thermal effect was investigated by the way of differential thermal analysis (DTA) in $\mathrm{N}_{2}$ ambient using a TG/DTA 6300 of Seiko Instruments SII. The gas rate was $100 \mathrm{~mL} / \mathrm{min}$, and the heating rate was $10 \mathrm{~K} / \mathrm{min}$.

CdTe-based solar cells of the superstrate configuration were fabricated. CdS and CdTe layers were sequentially deposited by chemical bath deposition and close-spaced sublimation on TCO-coated glass substrates. After deposition, the samples were submitted to a wet $\mathrm{CdCl}_{2}$ treatment at $400^{\circ} \mathrm{C}$ in air for $30 \mathrm{~min}$. Then an $\mathrm{Sb}_{2} \mathrm{Te}_{3}$ layer $(\sim 100 \mathrm{~nm})$ was deposited using the vacuum coevaporation technique at room temperature on the CdTe surface which was previously etched with Br-methanol. These samples were subsequently annealed in $\mathrm{N}_{2}$ ambient. Finally, Au was deposited by electron beam evaporation as the back electrodes. The typical structure of the cells was glass/TCO/CdS/CdTe/Sb $\mathrm{Te}_{3} / \mathrm{Au}$. The resulting photovoltaic devices were characterized using the light current voltage $(J-V)$ measurement under simulated AM1.5 illumination (i.e., $1000 \mathrm{~W} / \mathrm{m}^{2}$ ), dark $J-V$, and capacitance voltage $(C-V)$ measurements.

\section{Results and Discussion}

Figure 1 shows the XRD patterns of $624 \mathrm{~nm}$ thick Sb-Te alloy thin as-deposited films. The Sb-Te alloy thin films are amorphous at room temperature. To determine the composition of the Sb-Te alloy thin films, XRF spectra of Sb-Te alloys were carried out. XRF of as-deposited Sb-Te alloy thin films is shown in Figure 2. By calculating the peak area of Sb $\mathrm{K} \alpha\left(12.8^{\circ}\right)$ and $\mathrm{Te} \mathrm{K} \alpha\left(13.4^{\circ}\right)$, every square centimeter of SbTe film quality can be worked out to be 0.118 and $0.174 \mathrm{mg}$, respectively. Thus, the Te:Sb ratio is $1.41: 1$. Considering the errors caused by instruments and so on, these results are acceptable although the standard chemical ratio is $1.5: 1$. Therefore, the results show that the chemical composition of the thin films is $\mathrm{Sb}_{2} \mathrm{Te}_{3}$.

Figure 1 also shows Sb-Te alloy thin films annealed at different temperatures in $\mathrm{N}_{2}$ ambient, from which it indicates that the films are polycrystalline. As increasing the annealing temperature up to $439 \mathrm{~K}$, the thin films contain three peaks. One diffraction peak of $\mathrm{Sb}_{2} \mathrm{Te}_{3}$ at the angle of $26.322^{\circ}$ could be observed, while the other peaks are at angles of $28.671^{\circ}$ and $39.709^{\circ}$, corresponding to the (106) and (1012) planes of $\mathrm{Sb}_{7} \mathrm{Te}$, respectively. When annealed at about $488 \mathrm{~K}$, the pattern of the films is different from that of the films annealed at $439 \mathrm{~K}$. The peaks of $\mathrm{Sb}_{7} \mathrm{Te}$ are totally suppressed, and more diffraction peaks of $\mathrm{Sb}_{2} \mathrm{Te}_{3}$, such as (006), (015), (1010), (0111), (0015), (0018), (0210), (1019), and (0120), emerge with the peak of Sb

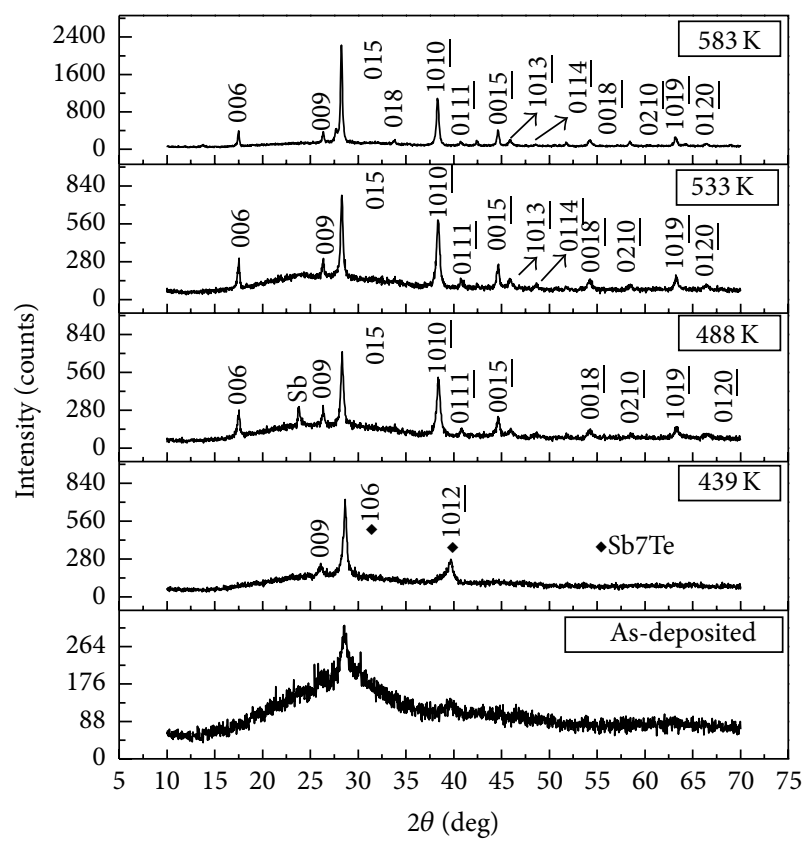

FIgURE 1: X-ray diffraction patterns of Sb-Te thin as-deposited films and annealed at different temperatures in $\mathrm{N}_{2}$ ambient.

at $23.688^{\circ}$. Peaks of $\mathrm{Sb}_{2} \mathrm{Te}_{3}$ (1013) and (0114) become more distinct and the phase of $\mathrm{Sb}$ disappears when the films are annealed at $533 \mathrm{~K}$. The peaks of $\mathrm{Sb}_{2} \mathrm{Te}_{3}$ become significantly strong when the films are annealed at $583 \mathrm{~K}$, and there are no other phases but $\mathrm{Sb}_{2} \mathrm{Te}_{3}$. This indicates that annealing promotes the formation of single phase $\mathrm{Sb}_{2} \mathrm{Te}_{3}$.

To explore the effect of annealing temperature on Sb-Te alloy thin films, DTA was performed. Figure 3 shows the differential thermal curve of as-deposited films. Unlike peaks of single crystal, whose reaction intervals were compressed into a small range, the peak of as-deposited Sb-Te alloy thin films was extended from 323 to $705 \mathrm{~K}$. And it was hard to figure out the base line, either at the initial temperature or at the final temperature. The negative DTA values meant endothermic reactions happened while heating. At first, DTA decreased because $\mathrm{Sb}$ atoms and $\mathrm{Te}$ atoms moved into lattice sites so as to get crystallized. As shown in Figure 1, lattice constant transition took place in the Sb-Te alloy thin films while annealing, and it ended at $488 \mathrm{~K}$. In addition, the decomposition of metastable $\mathrm{Sb}_{7} \mathrm{Te}$ occurred at about $439 \mathrm{~K}$; as the temperature was rising to about $533 \mathrm{~K}$, this reaction was accomplished. Energy consumption also took place during these processes. These results were verified by the differential thermal curve shown in Figure 3, in which the DTA value became more and more negative till the temperature reached up to $517 \mathrm{~K}$. After that, the DTA value elevated with increasing temperature, but it was still negative. This might be due to the fact that was the quantity of atoms that was involved in the relocation decreased and that implied that more and more atoms had moved to lattice sites then had been crystallized.

Based upon the results of DTA, X-ray diffraction patterns of the samples with different thicknesses annealed at $583 \mathrm{~K}$ were investigated as shown in Figure 4. Compared with 


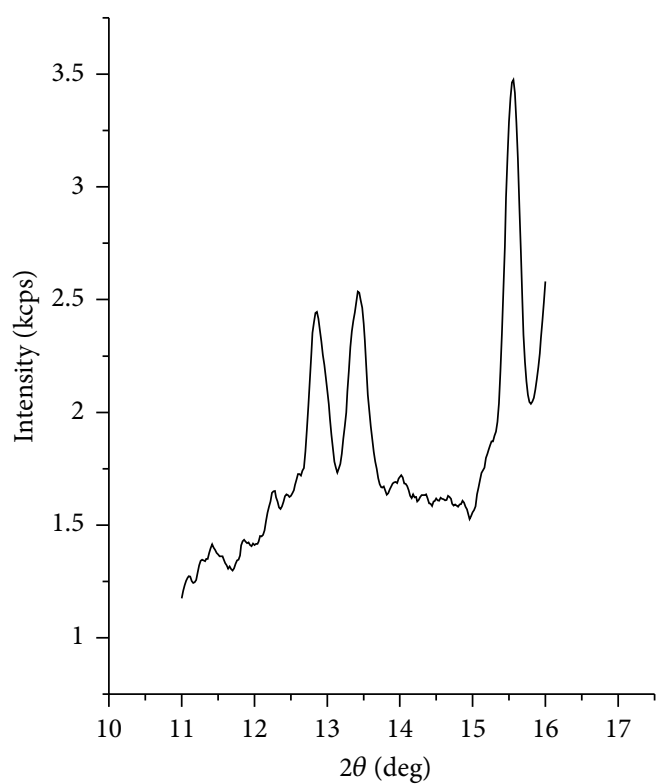

- Sb-KA

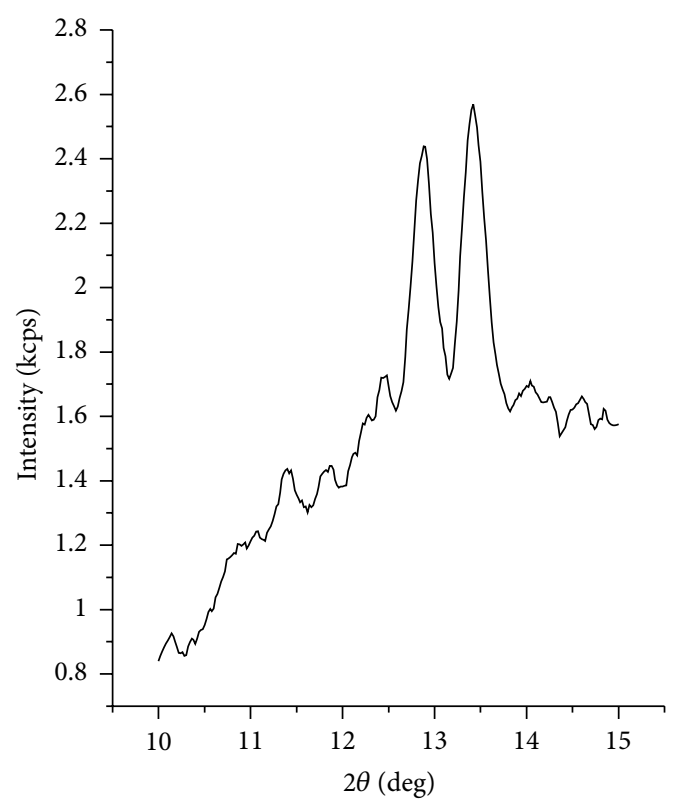

Te-KA

(a)

(b)

FiguRE 2: X-ray fluorescence of as-deposited Sb-Te alloy thin films.

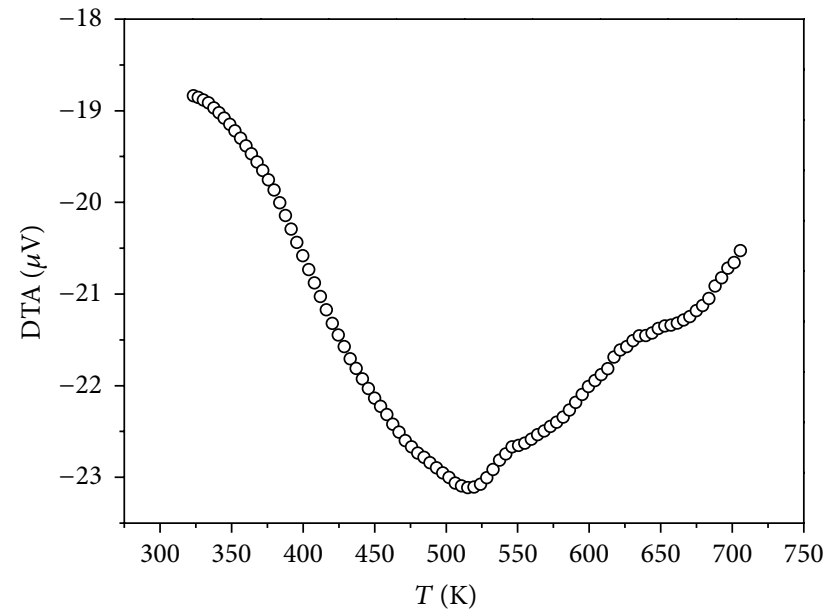

FIGURE 3: Differential thermal analysis of Sb-Te alloy thin films.

the samples with variable thicknesses, it can be concluded that trigonal $\mathrm{Sb}_{2} \mathrm{Te}_{3}$ obtained at above $267 \mathrm{~nm}$ is superior to others. In addition, the preferred orientation is at $28.244^{\circ}$ along the (015) planes and more peaks become distinct with the increase of thickness. Therefore, the results convincingly show that $\mathrm{Sb}_{2} \mathrm{Te}_{3}$ thin films can be prepared by coevaporation and annealing contributes to the grain growth.

As a buffer layer between the absorber layer and metal electrodes in the CdTe thin film solar cells, we investigated the electrical properties of Sb-Te alloy thin films by Hall measurements. Figure 5 shows the trends of Hall mobility and hole concentration against temperature. The carrier concentration of the order of $10^{19} \mathrm{~cm}^{-3}$ for the thin films was

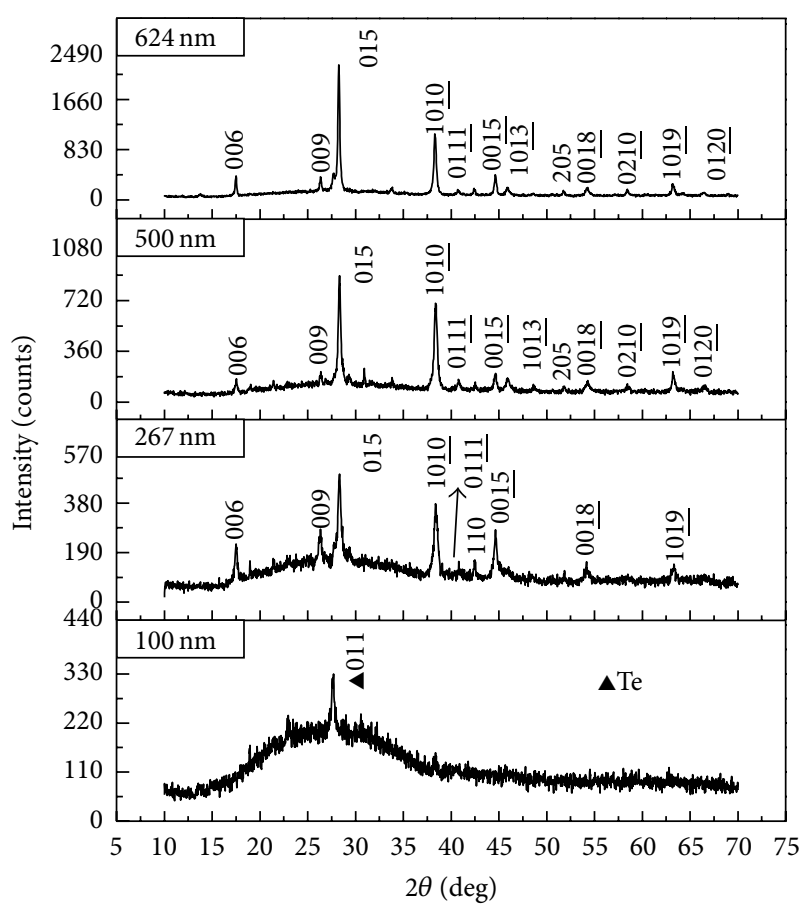

FIGURE 4: X-ray diffraction patterns of the samples with different thicknesses annealed at $583 \mathrm{~K}$.

obtained. The conduction type of the films was measured by the thermal probe method and the samples were proved to be all p-type conductors, which is consistent with the results of the Hall measurements. At the annealing temperature of $423 \mathrm{~K}$ the Hall mobility was rather small, only $8.86 \mathrm{~cm}^{2} / \mathrm{Vs}$. 


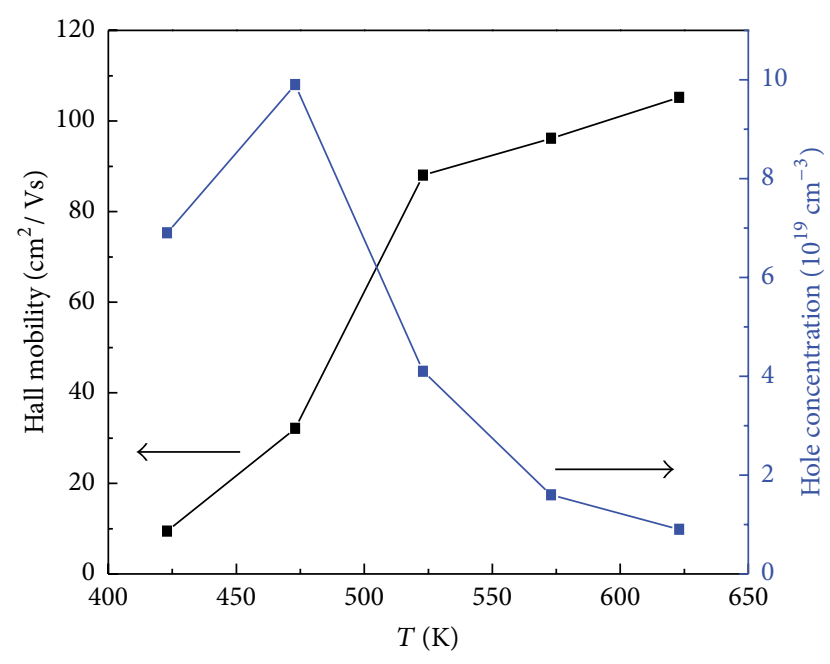

FIGURE 5: Electrical properties of the thin films annealed at different temperatures.

As the annealing temperatures increased, the carrier concentrations did not alter dramatically, while the mobility increased rapidly, especially at the temperature in the range from 423 to $525 \mathrm{~K}$. The impressive high values make it a promising back contact material for CdTe solar cells. The carrier mobility has the following relation:

$$
\mu_{p}=\frac{q \tau_{p}}{m_{p}}
$$

where $\mu_{p}$ is the mobility, $q$ is the electronic quantity, $\tau_{p}$ is the relaxation time, and $m_{p}$ is the effective mass. Because the carrier effective mass did not alter much, it is deduced that the increase of the mobility is due to the decrease of the relaxation time, which inverses to the scattering probability. As-deposited Sb-Te alloy thin films were amorphous, in which defects commonly exist. The quantity of defects is large enough to disregard other scattering mechanisms such as sonic scattering one and optical scattering one at a certain temperature. That means carriers are mostly scattered by defects in the $\mathrm{Sb}_{2} \mathrm{Te}_{3}$ thin films. After annealing, the number of defects is reduced significantly. Thus the scattering probability is also decreased, and the mobility is elevated. This is consistent with the results of XRD patterns as shown in Figures 1 and 4, in which the transition of Sb-Te alloy thin films from the amorphous Sb-Te phase into polycrystalline $\mathrm{Sb}_{2} \mathrm{Te}_{3}$ in the temperature range of $423-525 \mathrm{~K}$ is shown.

Meanwhile, the electrical conductivity of the as-deposited $\mathrm{Sb}-\mathrm{Te}$ alloy thin films was surveyed in the temperature range from 300 to $623 \mathrm{~K}$. The conductivity versus temperature plot is shown in Figure 6. The conductivity increases slowly with the increasing temperature. Then it increases dramatically in the temperature range about $385 \sim 455 \mathrm{~K}$. However, the conductivity slight alteration occurs as the temperature is higher than $455 \mathrm{~K}$. This kind of alteration can be attributed to the phase transition for the as-deposited films from the amorphous $\mathrm{Sb}-\mathrm{Te}$ phase into mixtures phases of polycrystalline $\mathrm{Sb}_{2} \mathrm{Te}_{3}$ and $\mathrm{Sb}_{7} \mathrm{Te}$ as evidenced by XRD and DTA

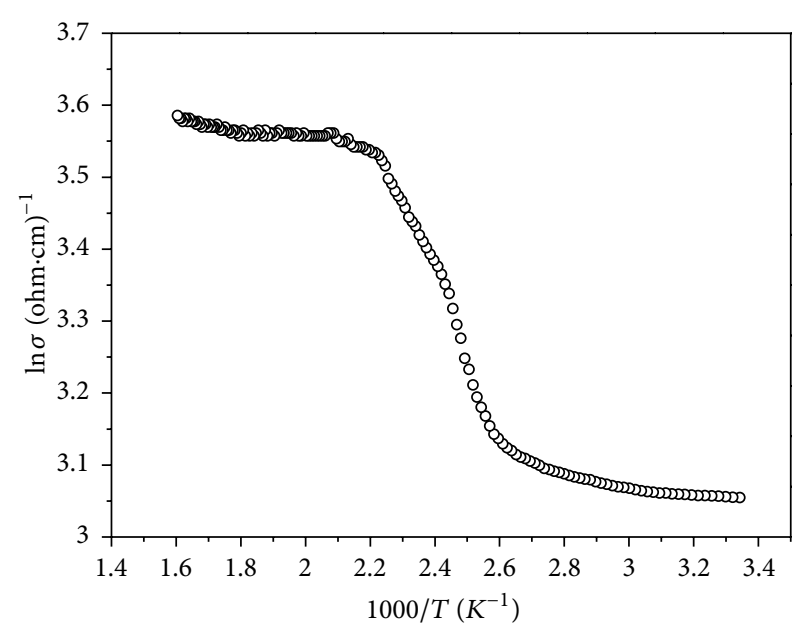

FIgURE 6: The temperature dependence of dark conductivity for SbTe alloy thin films.

investigations. This phenomenon was also observed by El Mandouh [15].

The aim of this work is to investigate the potential of antimony telluride films for solar cell applications. Thus, antimony telluride thin films were used as a back contact layer for CdS/CdTe solar cells. Before the deposition of antimony telluride films on the CdTe layer, an etching process was required. And then antimony telluride thin films were deposited. Finally the cells were annealed from 523 to $623 \mathrm{~K}$ based upon the studies mentioned above. Table 1 shows photovoltaic parameters for CdS/CdTe solar cells with or without antimony telluride buffer layers at different annealing temperatures. Obviously, cell performance in CdTe solar cells with $\mathrm{Sb}_{2} \mathrm{Te}_{3}$ is superior to those without the buffer layers. $\mathrm{Sb}_{2} \mathrm{Te}_{3}$ as the back contact layer of solar cells contributes to the improvement short circuit current $\left(J_{\mathrm{sc}}\right)$, open circuit voltage $\left(V_{o c}\right)$, and fill factor $(\mathrm{FF})$.

To further study the function of $\mathrm{Sb}_{2} \mathrm{Te}_{3}$ layers in back contact formation, the dark $J-V$ and $C-V$ characteristics for CdTe solar cells were measured (Figures 7 and 8). Figure 7 shows the dark $J-V$ curves of CdTe solar cells with or without $\mathrm{Sb}_{2} \mathrm{Te}_{3}$ back contact layers. Curve (a) reaches saturation when the voltage is higher than open circuit voltage, that is, rollover occurs. In contrast to curve (a), curve (b) increases with the elevating voltage. It can be assumed that the main reason devoted to the roll-over phenomenon is the high series resistance. Therefore, $\mathrm{Sb}_{2} \mathrm{Te}_{3}$ back contact layers can effectively improve the contact characteristics and reduce the series resistance.

Figure 8 shows the capacitance voltage curves of CdTe solar cells with/without $\mathrm{Sb}_{2} \mathrm{Te}_{3}$ back contact layers. One can see that curve (a) is upward when the external bias potential is $1.8 \mathrm{~V}$ or larger, while curve (b) is, on the contrary, straightly downward all the way. From these results we conclude that the reverse junction comes into being between the metal electrodes and p-type CdTe without $\mathrm{Sb}_{2} \mathrm{Te}_{3}$ back contact layers. And it is successfully eliminated when $\mathrm{Sb}_{2} \mathrm{Te}_{3}$ back contacts are deposited. The carrier concentrations from the two curves were obtained, curve (a) showing a result of 


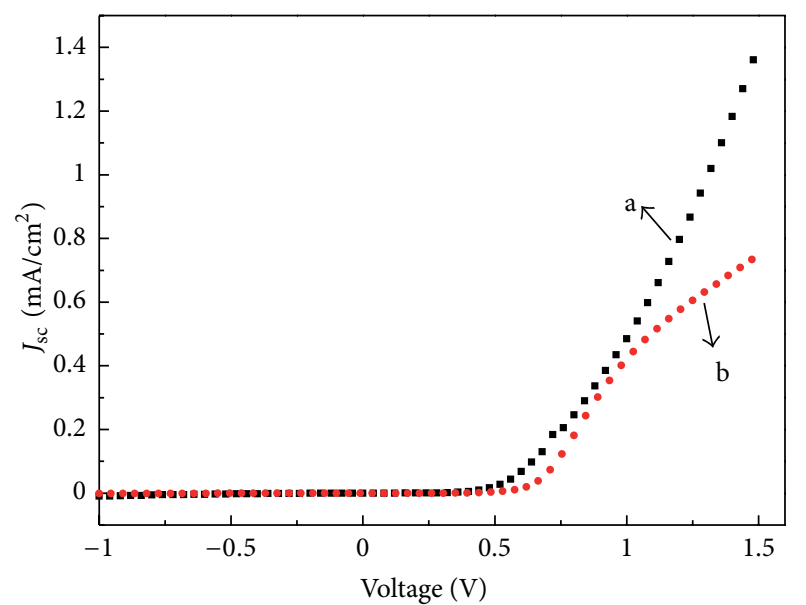

Figure 7: Dark $J-V$ curves for CdTe solar cells with $\mathrm{Sb}_{2} \mathrm{Te}_{3}$ (a) or without the back contact layer (b).

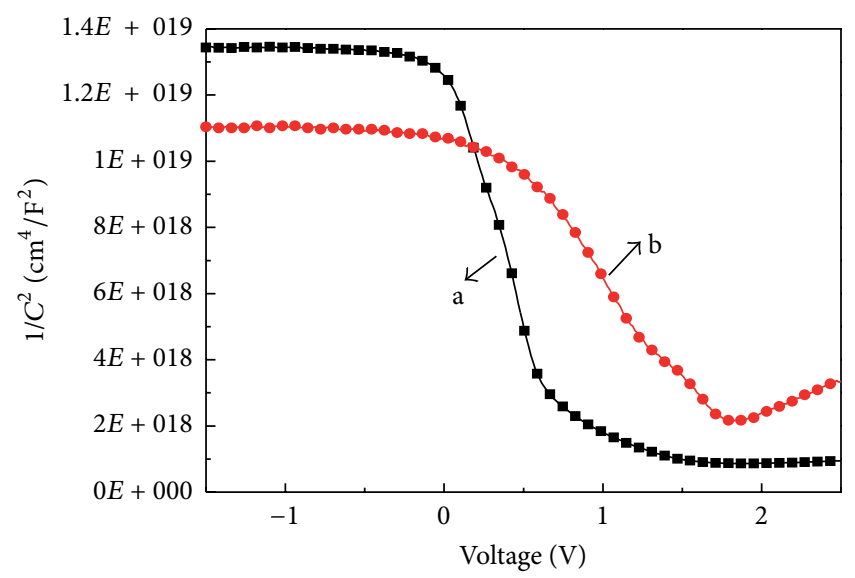

Figure 8: $1 / C^{2}-V$ curves for CdTe solar cells with $\mathrm{Sb}_{2} \mathrm{Te}_{3}$ (a) or without the back contact layer (b).

TABLE 1: The parameters for CdS/CdTe solar cells with or without $\mathrm{Sb}_{2} \mathrm{Te}_{3}$ back contacts at different annealing temperatures.

\begin{tabular}{lcccc}
\hline Temperature & $V_{\mathrm{oc}}(\mathrm{mV})$ & $J_{\mathrm{sc}}\left(\mathrm{mA} / \mathrm{cm}^{2}\right)$ & $\mathrm{FF}(\%)$ & $E_{\mathrm{ff}}(\%)$ \\
\hline Without back contacts & 720.9 & 20.3 & 54 & 7.9 \\
No annealing & 680.1 & 19.2 & 50 & 6.53 \\
$523 \mathrm{~K}$ & 743.7 & 23.5 & 55 & 9.61 \\
$573 \mathrm{~K}$ & 805.9 & 25.1 & 61 & 12.34 \\
$623 \mathrm{~K}$ & 784.9 & 24.3 & 58 & 11.06 \\
\hline
\end{tabular}

$3.89 \times 10^{13} / \mathrm{cm}^{3}$ while curve (b) $1.74 \times 10^{14} / \mathrm{cm}^{3}$. Obviously, the order of magnitude of carrier concentration can be increased when the $\mathrm{Sb}_{2} \mathrm{Te}_{3}$ back contacts was adopted.

\section{Conclusions}

Antimony telluride thin films were deposited at room temperature by the vacuum coevaporation method, and the results show that single $\mathrm{Sb}_{2} \mathrm{Te}_{3}$ phase exists when the annealing temperature is higher than $488 \mathrm{~K}$. The Hall mobility of
$\mathrm{Sb}_{2} \mathrm{Te}_{3}$ increases with the elevating annealing temperatures, while the carrier concentration decreases. With the application of a back contact material in CdTe thin film solar cells, we can effectively improve the short circuit current, open circuit voltage, and fill factor, thus greatly improving the conversion efficiency. The results also show that antimony telluride films can improve the contact characteristics between CdTe and the back electrodes, reduce the series resistance, and eliminate the effect of the reverse junction.

\section{Conflict of Interests}

The authors declare that there is no conflict of interests regarding the publication of this paper.

\section{Acknowledgments}

This work was supported by the National Basic Research Program of China (Grant no. 2011CBA007008), National Natural Science Foundation of China (Grant no. 61076058), and Science and Technology Program of Sichuan Province, China (Grant no. 2013GZX0145).

\section{References}

[1] M. A. Green, K. Emery, Y. Hishikawa, W. Warta, and E. D. Dunlop, "Solar cell efficiency tables (version 42)," Progress in Photovoltaics, vol. 21, pp. 827-837, 2013.

[2] A. L. Fahrenbruch, "Ohmic contacts and doping of CdTe," Solar Cells, vol. 21, no. 1-4, pp. 399-412, 1987.

[3] L. Wu, L. Feng, W. Li et al., "Effect of ZnTe/ZnTe:Cu complex back-contact on device characteristics of CdTe solar cells," Science in China E, vol. 50, no. 2, pp. 199-205, 2007.

[4] C. S. Ferekides, V. Viswanathan, and D. L. Morel, "RF sputtered back contacts for CdTe/CdS thin film solar cells," in Proceedings of the IEEE 26th Photovoltaic Specialists Conference (PVSEC '97), pp. 423-426, Anaheim, Calif, USA, October 1997.

[5] D. L. Bätzner, A. Romeo, H. Zogg, R. Wendt, and A. N. Tiwari, "Development of efficient and stable back contacts on CdTe/ CdS solar cells," Thin Solid Films, vol. 387, no. 1-2, pp. 151-154, 2001.

[6] D. L. Bätzner, A. Romeo, M. Terheggen, M. Döbeli, H. Zogg, and A. N. Tiwari, "Stability aspects in CdTe/CdS solar cells," Thin Solid Films, vol. 451-452, pp. 536-543, 2004.

[7] N. Romeo, A. Bosio, R. Tedeschi, A. Romeo, and V. Canevari, "Highly efficient and stable CdTe/CdS thin film solar cell," Solar Energy Materials and Solar Cells, vol. 58, no. 2, pp. 209-218, 1999.

[8] T. Schmidt, K. Durose, C. Rothenhäusler, and M. Lerch, "Chemical stability of $\mathrm{Sb}_{2} \mathrm{Te}_{3}$ back contacts to CdS/CdTe solar cells," Thin Solid Films, vol. 361-362, pp. 383-387, 2000.

[9] S. M. Sonawane and N. B. Chaure, "Studies on antimony telluride thin films as buffer layer for solar cell applications," Journal of Renewable and Sustainable Energy, vol. 5, Article ID 031612, 2013.

[10] P. Arun, P. Tyagi, A. G. Vedeshwar, and V. Kumar Paliwal, "Ageing effect of $\mathrm{Sb}_{2} \mathrm{Te}_{3}$ thin films," Physica B, vol. 307, no. 14, pp. 105-110, 2001.

[11] R. Venkatasubramanian, T. Colpitts, E. Watko, M. Lamvik, and N. El-Masry, "MOCVD of $\mathrm{Bi}_{2} \mathrm{Te}_{3}, \mathrm{Sb}_{2} \mathrm{Te}_{3}$ and their superlattice 
structures for thin-film thermoelectric applications," Journal of Crystal Growth, vol. 170, no. 1-4, pp. 817-821, 1997.

[12] P. Arun and A. G. Vedeshwar, "Influence of grain size on the electrical properties of $\mathrm{Sb}_{2} \mathrm{Te}_{3}$ polycrystalline films," Materials Research Bulletin, vol. 38, no. 15, pp. 1929-1938, 2003.

[13] B. Fang, Z. Zeng, and X. Yan, "Effects of annealing on thermoelectric properties of $\mathrm{Sb}_{2} \mathrm{Te}_{3}$ thin films prepared by radio frequency magnetron sputtering," Journal of Materials Science, vol. 24, pp. 1105-1111, 2013.

[14] S. Hu, Z. Zhu, W. Li et al., "Band diagrams and performance of CdTe solar cells with a $\mathrm{Sb}_{2} \mathrm{Te}_{3}$ back contact buffer layer," AIP Advances, vol. 1, no. 4, Article ID 042152, 2011.

[15] Z. S. El Mandouh, "Structure and electrical properties of vacuum-deposited antimony telluride thin films on an amorphous substrate," Journal of Materials Science, vol. 30, no. 5, pp. 12731276, 1995. 

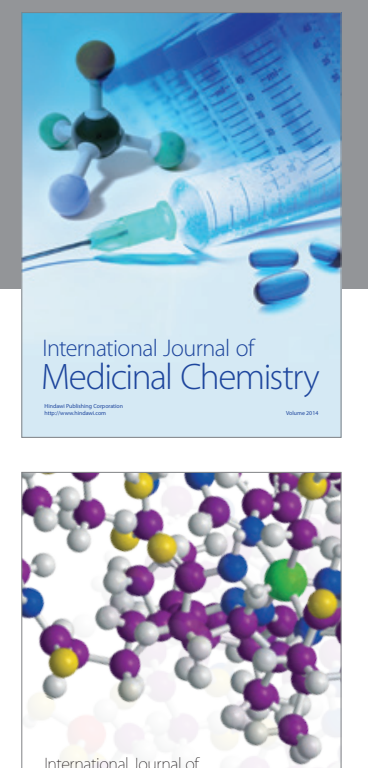

\section{Carbohydrate} Chemistry

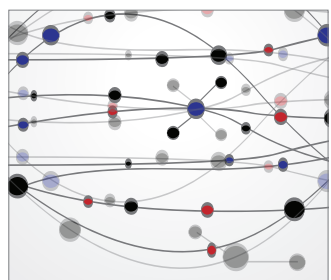

The Scientific World Journal
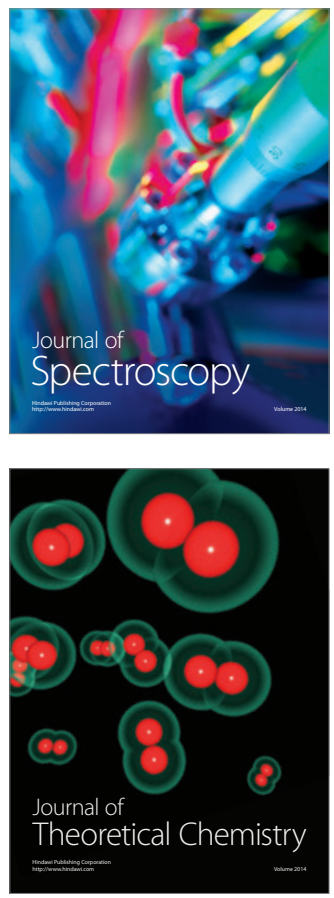
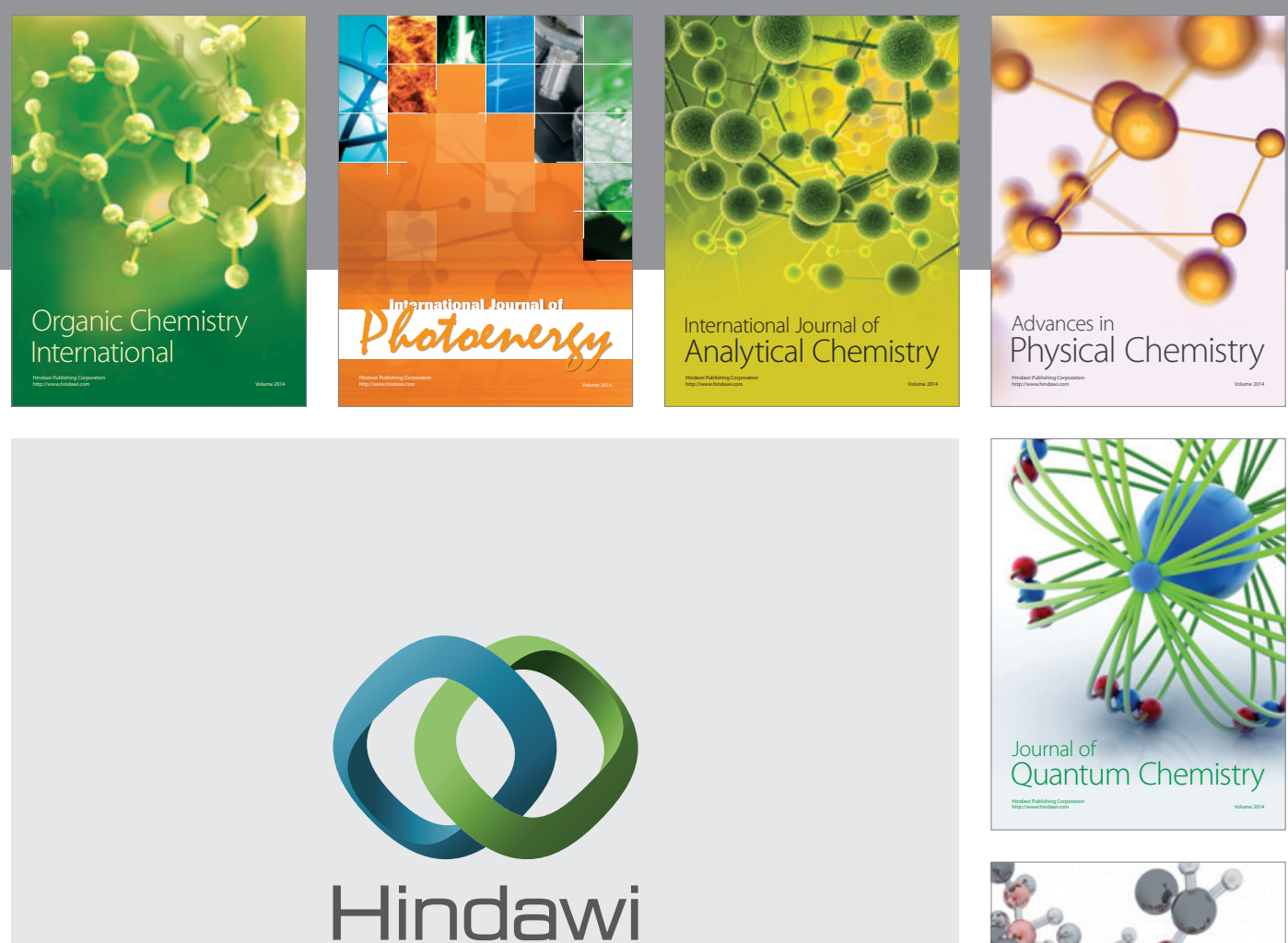

Submit your manuscripts at

http://www.hindawi.com

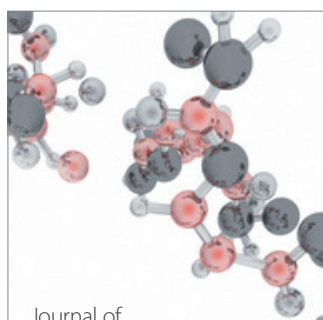

Analytical Methods

in Chemistry

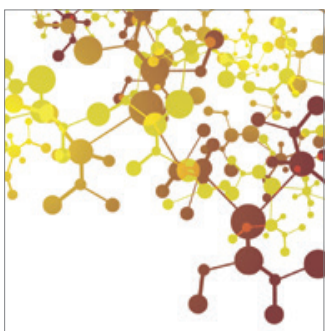

Journal of

Applied Chemistry

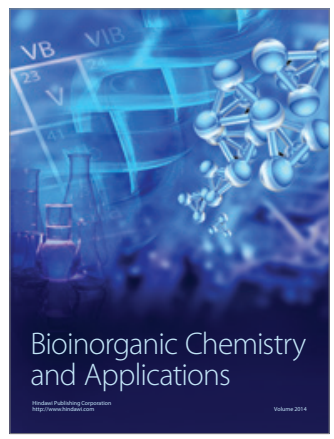

Inorganic Chemistry
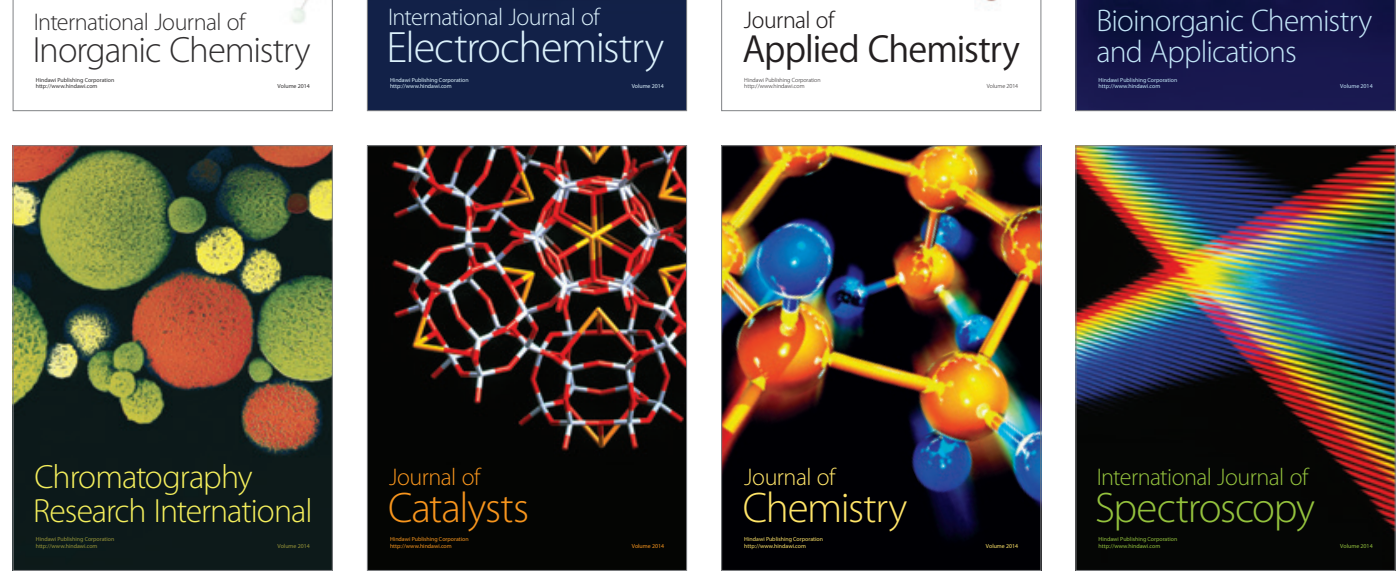